(2) Open Access Full Text Article

\title{
Preservative-free fixed combination of tafluprost $0.0015 \%$ and timolol $0.5 \%$ in patients with open-angle glaucoma and ocular hypertension: results of an open-label observational study
}

\author{
This article was published in the following Dove Press journal: \\ Clinical Ophthalmology \\ 2 June 2017 \\ Number of times this article has been viewed
}

\author{
Lutz E Pillunat ${ }^{1}$ \\ Carl Erb ${ }^{2}$ \\ Auli Ropo 3 \\ Friedemann Kimmich ${ }^{4}$ \\ Norbert Pfeiffer ${ }^{5}$ \\ 'Department of Ophthalmology, \\ University Hospital Carl Gustav \\ Carus, Dresden, ${ }^{2}$ Augenklinik am \\ Wittenbergplatz, Berlin, Germany; \\ ${ }^{3}$ Santen Europe, Helsinki, Finland; \\ ${ }^{4}$ eyecons, Pfinztal, ${ }^{5}$ Department of \\ Ophthalmology, Mainz University \\ Medical Center, Mainz, Germany
}

Correspondence: Lutz E Pillunat Department of Ophthalmology, University Hospital Carl Gustav Carus Fetscherstrasse 74, 0I307 Dresden, Germany

$\mathrm{Tel}+4935$ I 458338 I

$\mathrm{Fax}+493514584335$

Email augendirektion@

uniklinikumdresden.de
Background: Efficacy, tolerability and safety of the novel preservative-free fixed combination of tafluprost $0.0015 \% /$ timolol $0.5 \%$ (Taptiqom $^{\circledR}$ ) were investigated in an observational study in Germany.

Objective: To assess efficacy, tolerability and safety of the preservative-free fixed combination of tafluprost $0.0015 \% /$ timolol $0.5 \%$ in a real-life setting.

Methods: Intraocular pressure (IOP) was recorded for each eye at baseline (any previous therapy or untreated) and 4-16 weeks after changing medical treatment to or initiating treatment with the preservative-free fixed combination of tafluprost $0.0015 \% /$ timolol $0.5 \%$. Change in IOP was evaluated over the study period for all patients and for specific pretreatment subgroups. Clinical signs such as conjunctival hyperemia and lid-parallel conjunctival folds (LIPCOF) were recorded using standardized comparative photographs. Corneal staining, subjective symptoms and local comfort were measured using a four-step scale. All adverse events were recorded.

Results: Among 1,157 patients enrolled, 1,075 patients were treated with the preservativefree fixed combination as the only medication at the final visit. Medical treatment was initiated in 741 patients because of an insufficient IOP-lowering effect of the prior medication. In 343 patients, medication was changed because of tolerability issues. The preservative-free fixed combination lowered IOP significantly in the subgroup of naïve patients, all subgroups with prior monotherapy and patients with prior fixed combinations: naïve patients: $-8.9 \mathrm{mmHg}$, alpha2-agonists: $-6.4 \mathrm{mmHg}$, beta-blockers: $-5.7 \mathrm{mmHg}$, carbonic anhydrase inhibitors: $-5.2 \mathrm{mmHg}$, prostaglandins: $-4.7 \mathrm{mmHg}$, fixed-combination prostaglandins/timolol: $-2.4 \mathrm{mmHg}$. At the final visit, clinical signs and subjective symptoms were improved in patients with prior medical therapy. Local comfort was rated as "very good" or "good" by $89.1 \%$ of patients at the final visit. Only few adverse events occurred during the treatment period.

Conclusion: The preservative-free fixed combination of tafluprost $0.0015 \% /$ timolol $0.5 \%$ was effective, well tolerated and showed a good safety profile.

Keywords: fixed combination, tafluprost, timolol, glaucoma, preservative-free medication, preservatives

\section{Introduction}

Pharmacotherapy for glaucoma and ocular hypertension aims to lower intraocular pressure (IOP) to a target IOP level that is likely to be low enough to avoid the progression of glaucomatous optic neuropathy or the conversion from ocular hypertension to glaucoma. Usually medical treatment is initiated with a single topical hypotensive 
agent, a regimen that is also recommended by the European Glaucoma Society (EGS). ${ }^{1}$ Monotherapy, however, may be insufficient in many patients, because target pressure is not achieved and/or glaucoma progression cannot be prevented by use of a single agent. In those eyes a combination therapy is indicated. ${ }^{1}$ In Denmark, $40 \%$ of patients are treated with a combination of antiglaucoma drugs, ${ }^{2}$ while in 2010 in Germany, 22.5\% of all prescriptions for the treatment of patients with glaucoma and ocular hypertension covered by the social health insurances were fixed combinations. ${ }^{3}$ The Ocular Hypertensive Treatment Study showed that after a treatment period of 5 years, about $40 \%$ of patients require two medications to achieve a $20 \%$ IOP reduction from baseline, and additional $9 \%$ of the patients needed three or more medications. ${ }^{4}$ Thus, many glaucoma patients require a combination of different medications for adequate IOP control. A combination of drugs from different classes with various modes of actions can be applied either as two separate medications or as a fixed combination. Fixed combinations provide numerous potential benefits when compared with nonfixed combinations: they require fewer drops to be applied compared with nonfixed combinations and, thus, may improve adherence, providing a lower risk for washout compared with a subsequent instillation of medications and decrease the exposure to preservatives. ${ }^{5-8}$ A recently published clinical study confirms that the fixed combination of tafluprost $0.0015 \%$ and timolol $0.5 \%$ is equivalent to the nonfixed combination of tafluprost $0.0015 \%$ and timolol $0.5 \%$ dosed concomitantly in terms of IOP control and safety. ${ }^{9}$ Furthermore, it was shown that this preservative-free fixed combination is superior to both preservative-free tafluprost $0.0015 \%$ and preservative-free timolol $0.5 \% .^{10}$

Benzalkonium chloride (BAK) is widely used in glaucoma eyedrops as a preservative. BAK, however, is proapoptotic, proinflammatory and it causes damage of the tear film by disrupting the lipid layer and shows a negative impact on the number of conjunctival goblet cells. ${ }^{11-16}$ These negative effects of BAK and the related clinical symptoms may be avoided by using preservative-free formulations. ${ }^{17-19}$ Tafluprost was the first prostaglandin analog (PGA) that became available in a preservative-free formulation. The preservative-free fixed combination of this PGA and timolol may also offer benefits for some glaucoma patients. The present observational study was designed to evaluate the IOPlowering efficacy, tolerability and safety of the preservativefree fixed combination of tafluprost $0.0015 \%$ /timolol $0.5 \%$ ophthalmic solution in a natural clinical setting under real-life conditions in patients with open-angle glaucoma or ocular hypertension.

\section{Material and methods Study design}

This prospective, observational open-label multicenter study was conducted in 311 centers (office-based ophthalmologists) in Germany between January 2015 and September 2015. Each center provided anonymous data of up to five patients with ocular hypertension or glaucoma. The decision for initiating medical treatment with the preservative-free fixed combination of tafluprost $0.0015 \%$ and timolol $0.5 \%$ (Taptiqom) or the change of a prior medication to the preservative-free tafluprost/timolol fixed combination was based on the decision of the physician, and the reasons for changing medical therapy (eg, insufficient IOP-lowering effect of prior medication, progression or conversion, poor tolerability of prior medication, compliance issues) were recorded. German health authorities such as the Federal Institute for Medicinal Products (BfArM), the German Medical Association and the National Associations of Statutory and Private Health Insurance Funds were notified about the study prior to the start according to the rules for conducting observational studies in Germany. German law does not require informed consent and ethics approval for these types of studies. Patients with glaucoma or ocular hypertension who required a change of medication or treatment-naïve patients were followed for 4-16 weeks after changing medication to, or initiation of treatment with, the preservative-free tafluprost/timolol fixed combination once daily. At baseline, demographics, diagnoses and information on prior medical treatment were recorded and IOP readings, clinical signs and subjective symptoms were documented. IOP measurements were made for each eye at baseline (on prior treatment or without treatment in naïve patients) and also at final visit 4-16 weeks after changing prior medication or the initiation of the medical treatment with the preservative-free tafluprost/timolol fixed combination. No washout period was required because of the observational type of the study. IOP readings were performed using only Goldmann applanation tonometry. Due to the observational character of the study no instructions beside the summary of product characteristics for Taptiqom (summary of product characteristics [SmPC]) were given to the participating ophthalmologists especially concerning the time of IOP measurements during the day and the time point for the administration of the medication during the day (evening or morning dose). 
The clinical signs such as conjunctival hyperemia and lid-parallel conjunctival folds (LIPCOF) were determined by using reference photographs. Conjunctival hyperemia was evaluated with a four-point scale (none, mild, moderate, severe) and LIPCOF with a five-point grading scale (LIPCOF 0-4). Conjunctival staining was assessed subjectively without reference photographs by using a four-point scale (none, light, medium, intense). The severity of subjective symptoms such as dry eye sensation, irritation, itching, foreign body sensation and eye pain were evaluated at baseline and final visit. The patients were asked by the physician to rate these subjective symptoms on a four-step scale (none, mild, moderate, severe). Overall the local tolerance of the preservative-free tafluprost/timolol fixed combination was evaluated at the final visit using a four-step scale (very good, good, satisfactory, bad). At the final visit, efficacy and clinical signs were compared to the prior medical treatment in patients that were switched to the preservative-free tafluprost/timolol fixed combination (better, same or worse as compared to prior treatment). The main outcome measure of this study was the change of IOP from baseline to the final visit. Secondary outcome measures included the evaluation of the change of clinical signs and subjective symptoms from baseline to final visit and the adverse events reported during the study.

\section{Patients and statistics}

The study included patients with different types of glaucoma and ocular hypertension, primarily those with insufficient IOP control and tolerability issues with prior medical therapy. In total, 1,157 patients met the inclusion criteria and were eligible for the evaluation. Patients were excluded from the evaluation with a follow-up period between baseline and final visit of $<4$ weeks or $>16$ weeks. For the evaluation of efficacy, clinical signs, subjective symptoms and local comfort, patients were included who were treated with the preservative-free tafluprost/timolol fixed combination as the only medication at the final visit $(\mathrm{N}=1,075)$. IOP values after treatment with the preservative-free tafluprost/timolol fixed combination were compared to IOP values at baseline with paired $t$-tests. In case both eyes were treated, the eye with the higher baseline IOP was included in the IOP analysis. Bowker's test of symmetry was used for statistical evaluation of changes of clinical signs (hyperemia) and subjective symptoms. All statistical evaluations were done in Excel and by using in-house statistical software. All adverse reactions and terminations of medical treatment with the preservativefree tafluprost/timolol fixed combination were recorded.

\section{Results Prior medical therapy and patient demographics}

The majority of patients were on medical glaucoma therapy at baseline $(88.9 \%)$. One hundred twenty-eight patients (11.1\%) were naïve to treatment. Most patients were treated with a monotherapy prior to enrollment (51.9\%), most frequently with a PGA (29.4\%). Four hundred and twenty-nine patients $(37.1 \%)$ were treated with either fixed or nonfixed combinations. An overview of patients enrolled in the study by treatment is summarized in Table 1.

The mean age of the patients was $67.8 \pm 12.8$ years (range: 21-104 years). As shown in Table 2, the majority of patients were female and suffered from primary open-angle glaucoma (70.9\%) or ocular hypertension (11.5\%).

Table I Treatment regimens before and after initiating treatment with the preservative-free fixed combination tafluprost $0.0015 \% /$ timolol $0.5 \%$

\begin{tabular}{|c|c|c|c|}
\hline $\begin{array}{l}\text { Type of treatment/ } \\
\text { active agent }\end{array}$ & $\begin{array}{l}\text { PF TTFC } \\
\text { only }\end{array}$ & $\begin{array}{l}\text { PF TTFC } \\
\text { adjunctive }\end{array}$ & Total \\
\hline & $\mathbf{N}$ & $\mathbf{N}$ & $\mathbf{N}$ \\
\hline Naïve patients & 127 & 1 & 128 \\
\hline Monotherapy & 578 & 22 & 600 \\
\hline Beta-blocker & 163 & 1 & 164 \\
\hline PGA & 338 & 2 & 340 \\
\hline CAl & 48 & 12 & 60 \\
\hline Alpha-2-agonist & 28 & 7 & 35 \\
\hline Miotic & I & 0 & I \\
\hline Nonfixed combinations, two agents & 97 & 23 & 120 \\
\hline PGA + beta-blocker & 55 & I & 56 \\
\hline $\mathrm{PGA}+\mathrm{CAl}$ & 18 & II & 29 \\
\hline PGA + alpha-2-agonist & 7 & 9 & 16 \\
\hline CAI + beta-blocker & 8 & 0 & 8 \\
\hline $\mathrm{CAl}+$ alpha-2-agonist & 2 & 0 & 2 \\
\hline Alpha-2-agonist + beta-blocker & 6 & I & 7 \\
\hline Alpha-2-agonist + miotic & 0 & 1 & I \\
\hline PGA + miotic & I & 0 & I \\
\hline Fixed combinations, two agents & 238 & 4 & 242 \\
\hline Latanoprost/timolol & 47 & I & 48 \\
\hline Bimatoprost/timolol & 80 & 0 & 80 \\
\hline Travoprost/timolol & 36 & 0 & 36 \\
\hline Dorzolamide/timolol & 50 & 1 & 51 \\
\hline Brinzolamide/timolol & 16 & 0 & 16 \\
\hline Brimonidine/timolol & 6 & 0 & 6 \\
\hline Brinzolamide/brimonidine & 0 & 2 & 2 \\
\hline Miotic/timolol & 3 & 0 & 3 \\
\hline $\begin{array}{l}\text { Nonfixed combinations, } \\
\geq 3 \text { active agents }\end{array}$ & 35 & 32 & 67 \\
\hline$\geq 3$ active agents & 35 & 32 & 67 \\
\hline Total & 1,075 & 82 & $\mathrm{I}, 157$ \\
\hline
\end{tabular}

Abbreviations: CAI, carbonic anhydrase inhibitor; PGA, prostaglandin analog; PF TTFC, preservative-free tafluprost/timolol fixed combination. 
Table 2 Patient characteristics of the patient population $(\mathrm{N}=\mathrm{I}, \mathrm{I57})$ included in the observational study with the preservative-free fixed combination of tafluprost $0.0015 \%$ and timolol $0.5 \%$

\begin{tabular}{lll}
\hline Parameter & N & $\%$ \\
\hline Gender & & \\
Female & 688 & 59.5 \\
Male & 469 & 40.5 \\
Diagnosis & & \\
POAG & 820 & 70.9 \\
OH & 133 & 11.5 \\
NTG & 81 & 7.0 \\
PEX & 73 & 6.3 \\
PG & 18 & 1.6 \\
Other & 32 & 2.8 \\
Age & & \\
Range & $21-104$ & \\
Mean & 67.8 & \\
SD & 12.8 & \\
N/D & $n=5$ & \\
\hline
\end{tabular}

Abbreviations: NTG, normal tension glaucoma; N/D, no data; $\mathrm{OH}$, ocular hypertension; PEX, exfoliative glaucoma; PG, pigmentary glaucoma; POAG, primary open-angle glaucoma; SD, standard deviation.

\section{Reasons for changing prior medication}

Insufficient IOP-lowering effect assessed by the investigator was the most frequent reason for changing medication accounting for $72.0 \%$ of changes, followed by poor local tolerability (33.3\%), progression of glaucoma, lack of compliance and a conversion from ocular hypertension to glaucoma. Details are shown in Figure 1.

\section{Effect on IOP}

In the patient population that was used for the efficacy evaluation $(\mathrm{N}=1,075)$, the mean IOP was significantly reduced from

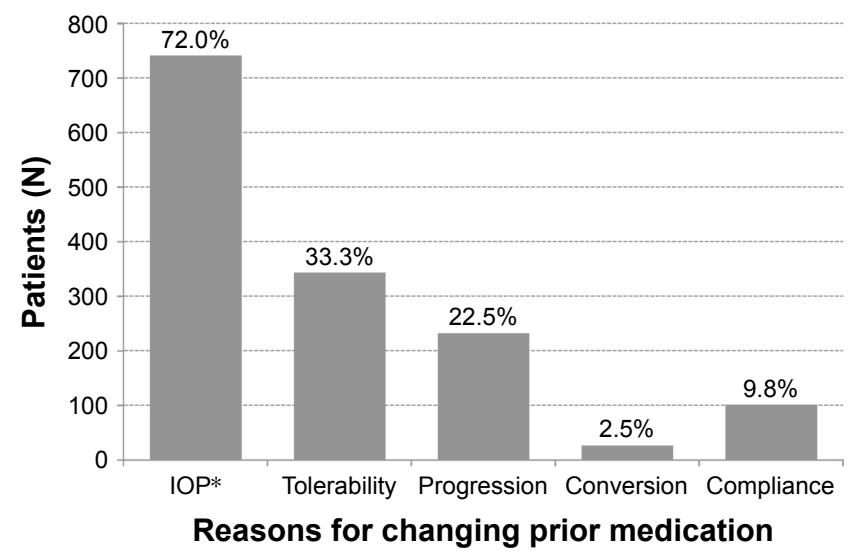

Figure I Reasons for changing medication to preservative-free tafluprost/timolol fixed combination.

Notes: Reporting of multiple reasons for changing medication was possible. Percentages given above the bars based on $\mathrm{N}=1,029$ patients with prior medication irrespective of treatment after change of medication. *Insufficient IOP lowering effect of prior medication(s).

Abbreviation: IOP, intraocular pressure.
$21.4 \pm 4.6 \mathrm{mmHg}$ at baseline to $16.5 \pm 3.4 \mathrm{mmHg}$ at final visit $(P<0.001)$ after initiation or change of medical therapy to the preservative-free tafluprost/timolol fixed combination. Among all patients $(\mathrm{N}=1,075)$ an IOP reduction of $\geq 20 \%$ compared to baseline was achieved by $56.5 \%$, of $\geq 30 \%$ by $25.7 \%$ and $\geq 40 \%$ by $10.3 \%$ of the patients. In the subgroup of treatment-naïve patients, IOP reduction of $\geq 20$, $\geq 30$ and $\geq 40 \%$ was achieved by $88.2,53.5$ and $27.6 \%$ of the patients, respectively.

Overall the IOP was lower at the final visit compared to the IOP at baseline in $89.5 \%$ of the eyes, equal in $5.1 \%$ and higher in $5.4 \%$ of all eyes (Figure 2 ).

\section{IOP in treatment-naïve patients and patients with prior monotherapy}

In treatment-naïve patients mean IOP decreased from $25.8 \pm 5.5$ to $16.9 \pm 2.9 \mathrm{mmHg}(P<0.001)$ after initiation of medical treatment $(-34.3 \%)$. In patients with prior PGA monotherapy, mean IOP was decreased from $21.0 \pm 3.7 \mathrm{mmHg}$ at baseline to $16.3 \pm 3.6 \mathrm{mmHg}(-22.3 \% ; P<0.001)$, in patients with prior beta-blockers from $22.4 \pm 3.3$ to $16.7 \pm 2.7 \mathrm{mmHg}$ $(-25.4 \% ; P<0.001)$, in patients with prior carbonic anhydrase inhibitors from $20.9 \pm 3.7$ to $15.7 \pm 2.8 \mathrm{mmHg}(-25.0 \%$; $P<0.001)$ and in patients with prior alpha-2-agonists from $23.1 \pm 5.1$ to $16.7 \pm 3.4 \mathrm{mmHg}(-27.6 \% ; P<0.001)$, respectively. In Figure 3 , the mean $\mathrm{IOP} \pm \mathrm{SD}$ is shown for

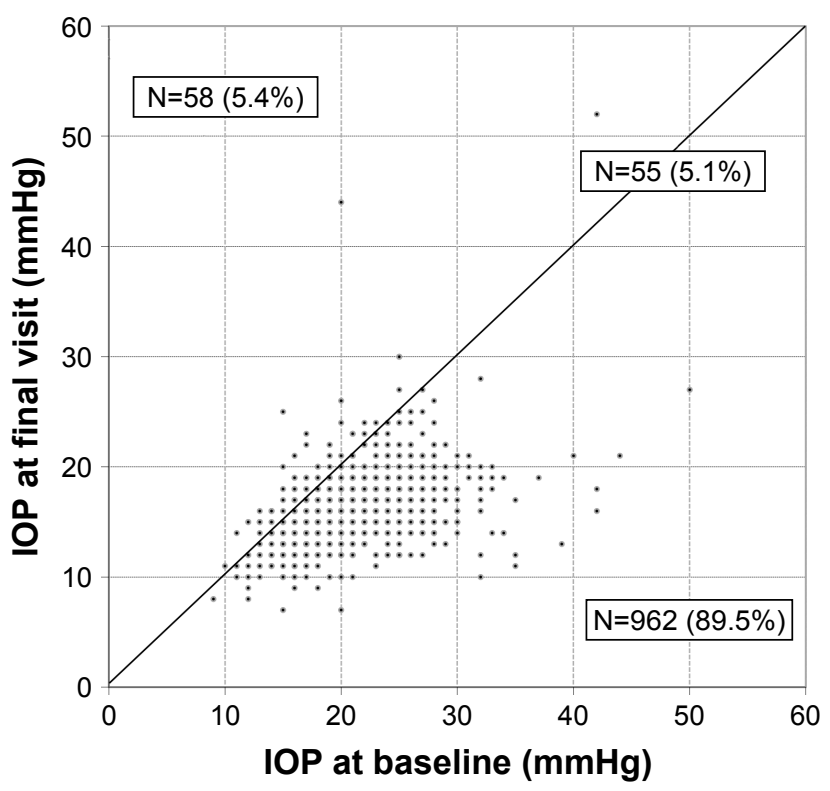

Figure 2 IOP at baseline and at final visit in each individual patient irrespective of prior treatment with the preservative-free tafluprost/timolol fixed combination as the only medication at final visit $(\mathrm{N}=\mathrm{I}, 075)$.

Note: IOP was lower at final visit in $\mathrm{N}=962$ (89.5\%) eyes (below the line), unchanged in $\mathrm{N}=55$ (5.1\%) eyes (on the line) and higher in $\mathrm{N}=58$ (5.4\%) eyes (above the line). Abbreviation: IOP, intraocular pressure. 


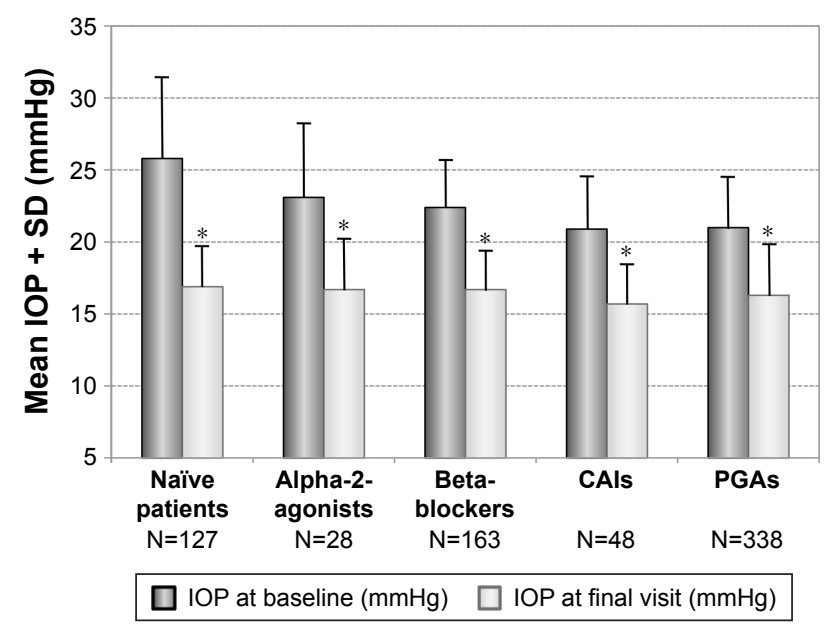

Figure 3 Decrease of mean IOP $( \pm S D)$ for different subgroups: Naïve patients $(\mathrm{N}=127)$ and patients with prior monotherapy with beta-blockers $(\mathrm{N}=163)$, PGAs $(\mathrm{N}=338)$, carbonic anhydrase inhibitors $(\mathrm{N}=48)$ and alpha-2-agonists $(\mathrm{N}=28)$ treated with the preservative-free tafluprost/timolol fixed combination as the only medication at final visit.

Note: $* P<0.001$

Abbreviations: CAls, carbonic anhydrase inhibitors; IOP, intraocular pressure; PGAs, prostaglandin analogs; SD, standard deviation.

treatment-naïve patients and the subgroups of patients with prior monotherapy.

In patients who were treated with a PGA monotherapy prior to change of medication, mean IOP was lowered from $21.1 \pm 3.4$ to $16.4 \pm 3.2 \mathrm{mmHg}(-22.3 \%)$, in patients with prior preserved latanoprost from $20.9 \pm 3.3$ to $16.2 \pm 2.9 \mathrm{mmHg}$ $(-22.6 \%)$, in patients with prior preservative-free latanoprost from $21.4 \pm 3.5$ to $16.7 \pm 3.8 \mathrm{mmHg}(-21.7 \%)$, in patients with prior preserved bimatoprost from $20.3 \pm 4.2$ to $16.2 \pm 5.0 \mathrm{mmHg}(-20.4 \%)$, in patients with prior preserved travoprost from $21.9 \pm 4.3$ to $15.9 \pm 3.3 \mathrm{mmHg}(-27.1 \%)$, in patients with prior preserved tafluprost from $20.2 \pm 2.9$ to $16.6 \pm 3.5 \mathrm{mmHg}(-18.0 \%)$ and in patients with prior preservative-free tafluprost from $21.2 \pm 3.9$ to $16.1 \pm 3.0 \mathrm{mmHg}$ $(-24.0 \%)$, respectively (Figure 4$)$. The IOP reduction was significant compared to the baseline pressure $(P<0.001)$ in each of these PGA monotherapy subgroups. Furthermore, two patients were treated with preservative-free bimatoprost prior to change of medication. IOP decreased in both patients from 17 to $15 \mathrm{mmHg}$ and from 18 to $15 \mathrm{mmHg}$, respectively. Due to the small sample size these two patients are not included in the statistical evaluation and are not shown in Figure 4.

\section{IOP in patients with prior fixed combinations}

Two hundred and thirty-eight patients were switched from prior treatment with a fixed combination. Of these

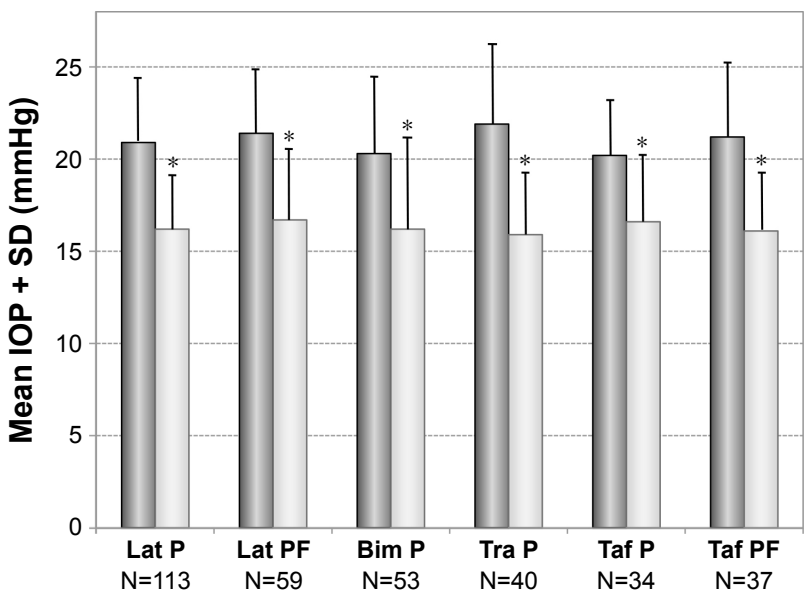

IOP at baseline $(\mathrm{mmHg}) \quad \square$ IOP at final visit $(\mathrm{mmHg})$

Figure 4 Decrease of mean IOP $( \pm S D)$ in patients with prior monotherapy with different prostaglandin analogs: preserved latanoprost (Lat $P ; N=I$ I3), preservativefree latanoprost (Lat PF; $N=59$ ), preserved bimatoprost (Bim $P ; N=53$ ), preserved travoprost (Tra $P ; N=40$ ), preserved tafluprost (Taf $P ; N=34$ ) and preservative-free tafluprost (Taf PF; $\mathrm{N}=37$ ) treated with preservative-free tafluprost/timolol fixed combination as the only medication at final visit.

Note: ${ }^{*} P<0.001$.

Abbreviations: IOP, intraocular pressure; SD, standard deviation.

238 patients, 163 patients were treated with a prostaglandin/ beta-blocker fixed combination, 66 patients with a carbonic anhydrase inhibitor/beta-blocker fixed combination and nine patients with other fixed combinations (three patients with pilocarpine/beta-blocker fixed combination and six patients with an alpha-2-agonist/beta-blocker fixed combination). The results for the subgroups of patients with prior fixed combinations who were switched to the preservative-free tafluprost/timolol fixed combination as the only medication at final visit are shown in Figure 5. The preservative-free fixed combination lowered mean IOP in patients with prior PGA/beta-blocker from $19.1 \pm 4.1 \mathrm{mmHg}$ at baseline to $16.7 \pm 3.1 \mathrm{mmHg}$ at final visit $(-12.7 \% ; P<0.001)$, in patients with prior carbonic anhydrase inhibitor/beta-blocker fixed combination from $20.7 \pm 4.2$ to $16.7 \pm 2.9 \mathrm{mmHg}(-19.3 \% ; P<0.001)$ and in patients with other fixed combinations from $21.7 \pm 4.1$ to $15.9 \pm 2.3 \mathrm{mmHg}(-26.7 \% ; P=0.007)$. Mean IOP was lowered in all preserved fixed combinations of a PGA and timolol between 3.2 and $2.1 \mathrm{mmHg}$. Details for the different preserved fixed combinations of PGAs and timolol are shown in Figure 6. In addition, mean IOP in a small subset of patients $(\mathrm{N}=7)$ with prior preservative-free bimatoprost/ timolol fixed combination decreased from $15.7 \pm 3.2 \mathrm{mmHg}$ at baseline to $14.9 \pm 2.3 \mathrm{mmHg}$ at the final visit $(-5.1 \%)$. The difference in this small sample size demonstrated no statistical significance $(P=0.29)$. 


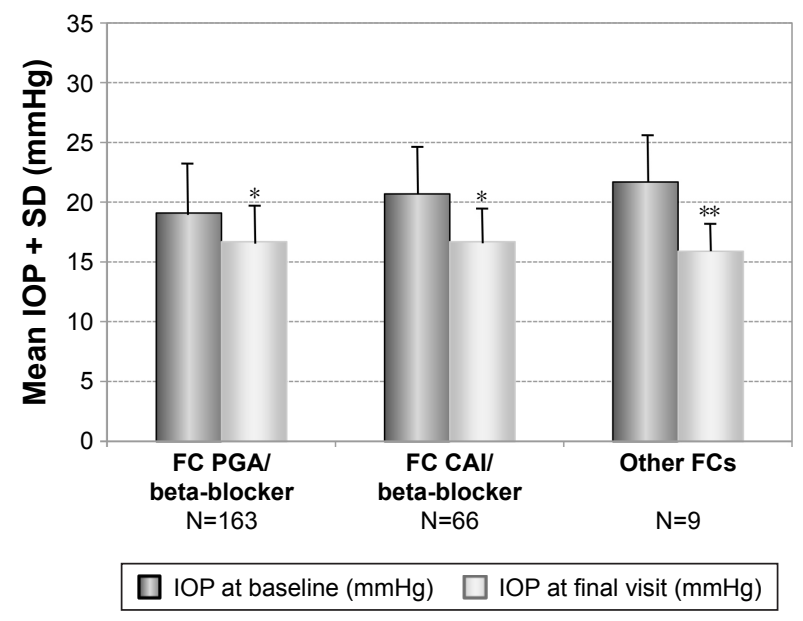

Figure 5 Decrease of mean IOP $( \pm S D)$ for different subgroups with prior fixed combinations: PGA/timolol ( $\mathrm{N}=163)$, carbonic anhydrase inhibitor/timolol $(\mathrm{N}=66)$ and other fixed combinations $(\mathrm{N}=9)$ treated with preservative-free tafluprost/ timolol fixed combination as the only medication at final visit.

Notes: $* P<0.001, * * P=0.007$.

Abbreviations: $\mathrm{CAl}$, carbonic anhydrase inhibitor; FC, fixed combination; IOP, intraocular pressure; PGA, prostaglandin analog; SD, standard deviation; TIM, timolol.

\section{IOP in patients with prior nonfixed combinations}

Overall 97 patients were treated with a nonfixed combination of two active ingredients before changing medication. In addition, 35 patients were treated with a nonfixed combination of three and more active ingredients. In the subgroup of patients with a nonfixed combination of two active ingredients, most patients $(\mathrm{N}=55)$ were treated with a nonfixed combination of a PGA + beta-blocker and with a PGA + carbonic anhydrase inhibitor $(\mathrm{N}=18)$. The results for these patients are shown in Figure 7. After changing medication, mean IOP was lowered in

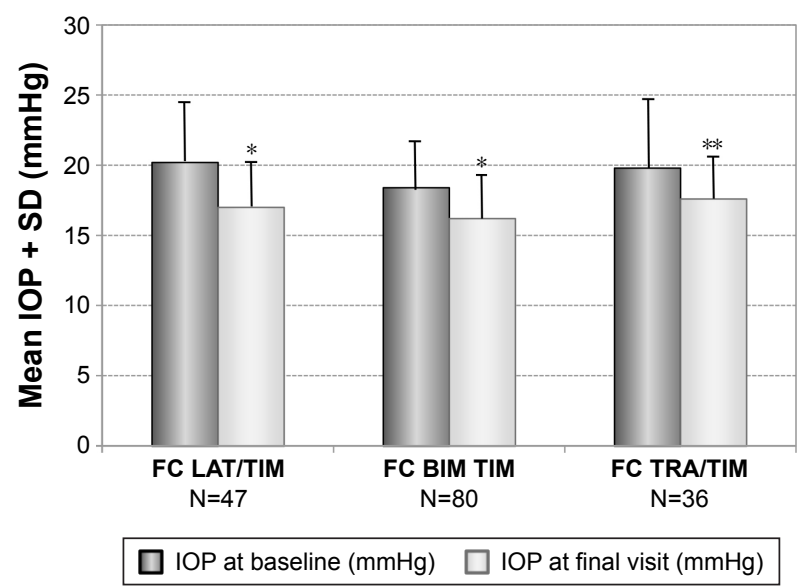

Figure 6 Decrease of mean IOP $( \pm S D)$ in patients with prior medical therapy with different preserved prostaglandin analog/timolol fixed combinations: latanoprost/ timolol $(\mathrm{N}=47)$, bimatoprost/timolol $(\mathrm{N}=73)$ and travoprost/timolol $(\mathrm{N}=36)$ treated with the preservative-free tafluprost/timolol fixed combination as the only medication at final visit.

Notes: $* P<0.001, * * P=0.058$.

Abbreviations: BIM, bimatoprost; FC, fixed combination; IOP, intraocular pressure; LAT, latanoprost; SD, standard deviation; TRA, travoprost; TIM, timolol.



Figure 7 Decrease of mean IOP $( \pm S D)$ for different subgroups with prior non-fixed combinations: PGA + beta-blocker $(\mathrm{N}=55), \mathrm{PGA}+$ carbonic anhydrase inhibitor $(\mathrm{N}=18)$ and nonfixed combinations of three different products $(\mathrm{N}=35)$ treated with the preservative-free tafluprost/timolol fixed combination as the only medication at final visit.

Notes: $* P<0.001, * * P=0.007, * * * P=0.005$.

Abbreviations: $\mathrm{CAl}$, carbonic anhydrase inhibitor; IOP, intraocular pressure; NFC, non-fixed combination; PGA, prostaglandin analog; SD, standard deviation.

patients with prior PGA + beta-blocker from $18.7 \pm 3.3 \mathrm{mmHg}$ at baseline to $16.0 \pm 3.2 \mathrm{mmHg}(-14.4 \% ; P<0.001)$, in patients with prior PGA + carbonic anhydrase inhibitor from $20.8 \pm 3.7$ to $17.2 \pm 4.7 \mathrm{mmHg}(-17.6 \% ; P=0.007)$ and in patients with prior nonfixed combination of three and more active ingredients from $20.8 \pm 6.3$ to $17.8 \pm 7.2 \mathrm{mmHg}$ $(-14.3 \% ; P=0.005)$, respectively.

\section{Effect of baseline IOP levels on the decrease of IOP}

The subgroup of treatment-naïve patients was stratified by the level of baseline IOP: the IOP-lowering effect of the preservative-free tafluprost/timolol fixed combination was highly dependent on the baseline pressure (Figure 8).

\section{Development of clinical signs and ocular symptoms \\ Clinical signs}

Overall the clinical signs (hyperemia, staining and LIPCOF) improved from baseline to the final visit: the development of the severity of hyperemia is shown in Figure 9 for all patients with prior medical treatment ( $\mathrm{N}=948)$, for treatment-naïve patients $(\mathrm{N}=127)$ and for specific subgroups of patients. At baseline conjunctival hyperemia was present in $65.5 \%$ of all patients with prior medical treatment. $5.5 \%$ of all patients with prior treatment had severe hyperemia at baseline. At the final visit conjunctival hyperemia was observed in $49.5 \%$ of all patients with prior medical treatment, and the percentage of patients suffering from a severe hyperemia decreased to 


\section{IOP at baseline $(\mathrm{mmHg})$}

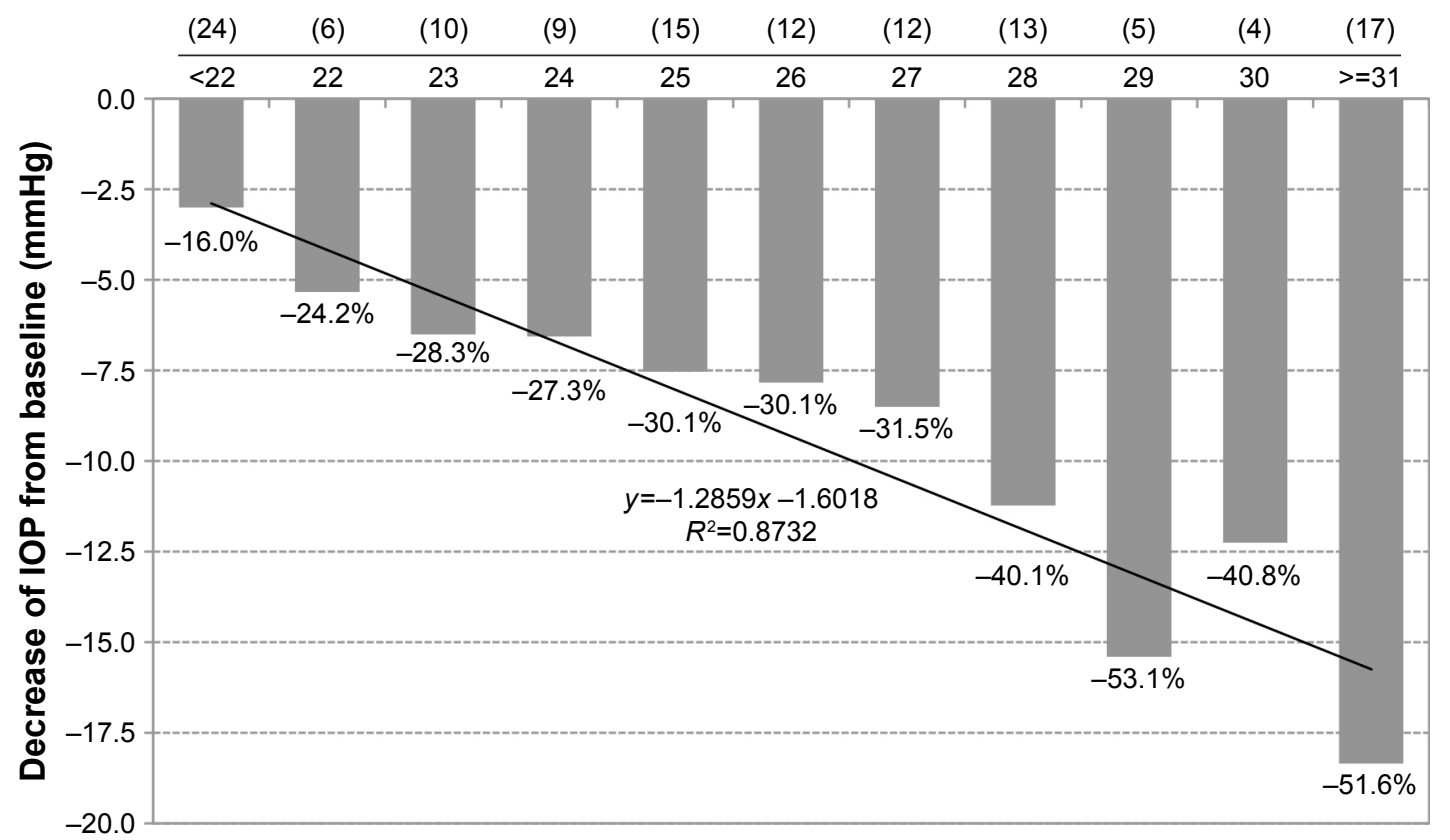

Figure 8 Decrease of IOP $(\mathrm{mmHg})$ from different baseline IOP levels in treatment-naïve patients after initiation of medical treatment with the preservative-free tafluprost/ timolol fixed combination ( $\mathrm{N}=127)$.

Note: Numbers in brackets indicate numbers of patients, percentages below bars indicate percentage decrease of IOP for each baseline IOP level.

Abbreviation: IOP, intraocular pressure.

$0.7 \%$. The analysis of conjunctival hyperemia for the different subgroups indicates that this clinical sign is more frequent in patient subgroups with prior medical treatments that include PGAs (either as monotherapy treatment regimens, fixed or nonfixed combinations). In all these patient subgroups a significant improvement of the severity was observed after changing medication (Figure 9). In the treatment-naïve patient population, the percentage of patients with mild and

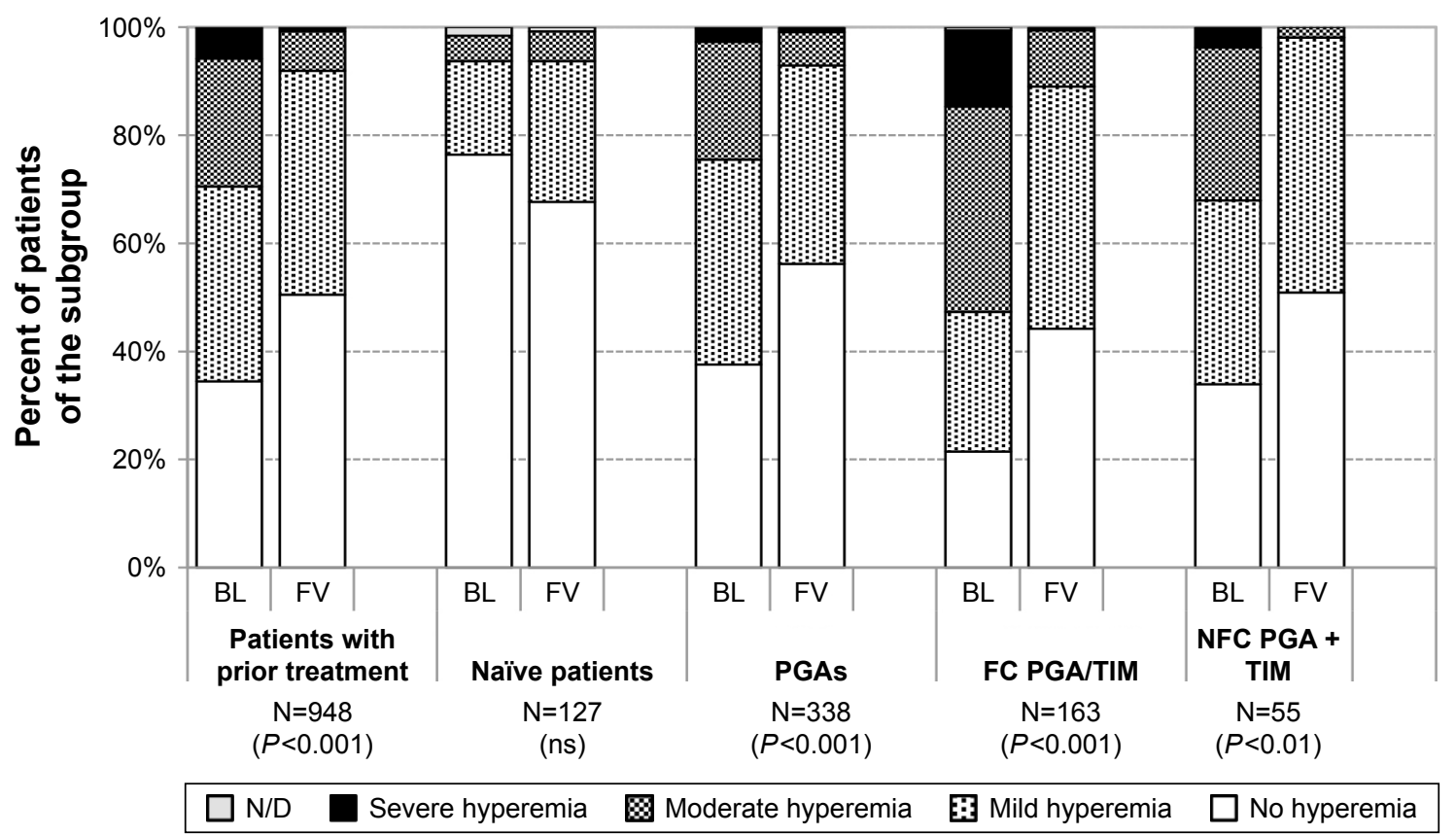

Figure 9 Conjunctival hyperemia at baseline and after initiation of medical therapy with or change of medication in patients treated with the preservative-free tafluprost/ timolol fixed combination as the only medication at final visit: All patients with prior medical therapy ( $\mathrm{N}=948)$, naïve patients ( $\mathrm{N}=127)$, patients with prior PGA monotherapy $(\mathrm{N}=338)$, patients with prior fixed combination PGA/timolol $(\mathrm{N}=163)$ and patients with prior non-fixed combinations of a PGA and timolol ( $\mathrm{N}=55)$.

Abbreviations: BL, baseline; FC, fixed combination; NFC, nonfixed combination; FV, final visit; PGA, prostaglandin analog; TIM, timolol; N/D, no data; ns, not significant. 


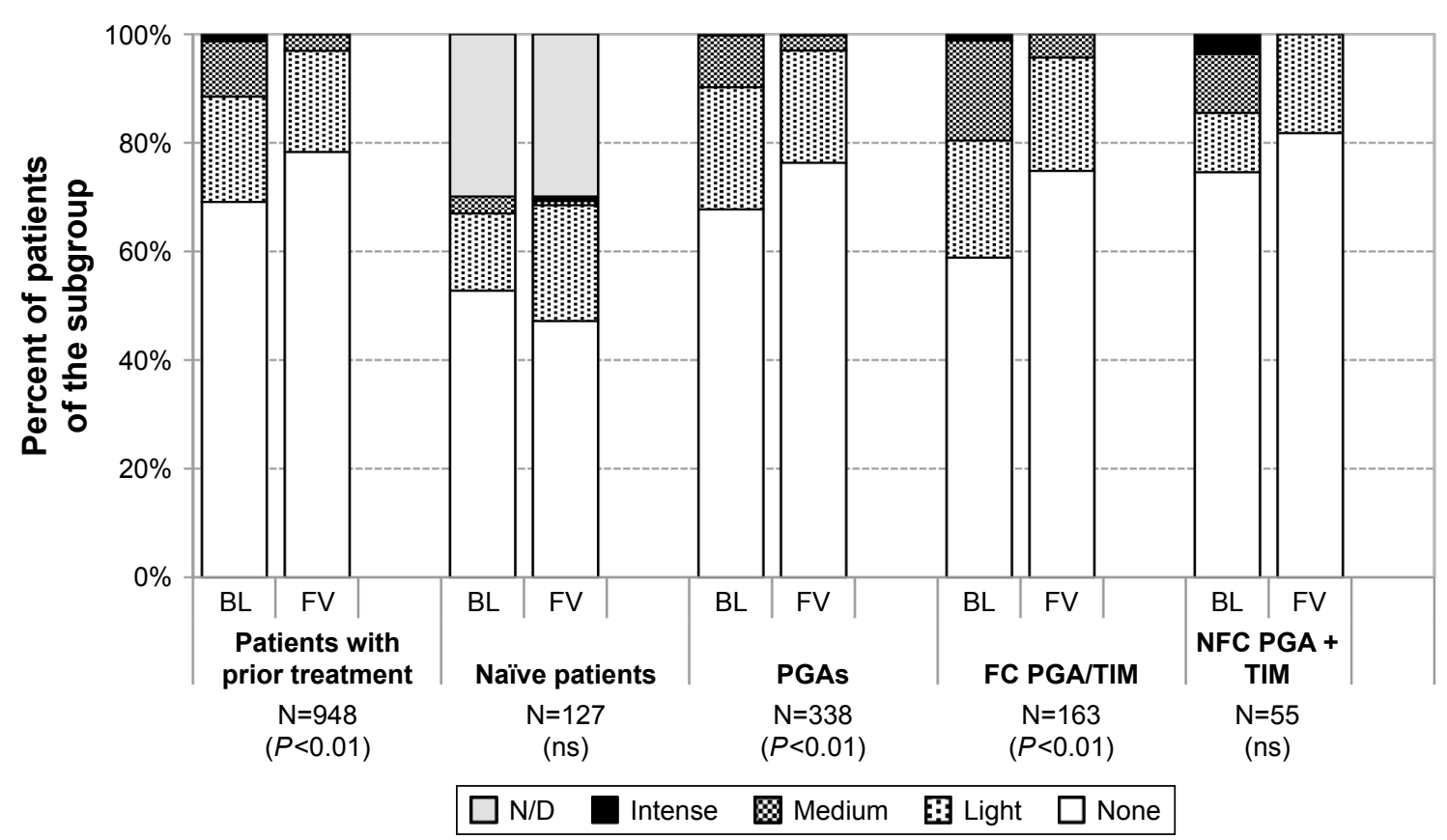

Figure 10 Conjunctival staining at baseline and after initiation of medical therapy with or change of medication in patients treated with preservative-free tafluprost/timolol fixed combination as the only medication at final visit: All patients with prior medical therapy ( $N=948$ ), naive patients ( $N=127)$, patients with prior PGA monotherapy $(\mathrm{N}=338)$, patients with prior fixed combination PGA/timolol $(\mathrm{N}=163)$ and patients with prior nonfixed combination of a PGA and timolol ( $\mathrm{N}=55)$.

Abbreviations: BL, baseline; FC, fixed combination; NFC, nonfixed combination; FV, final visit; PGA, prostaglandin analog; TIM, timolol; N/D, no data; ns, not significant.

moderate conjunctival hyperemia grading increased slightly from 22.0 to $31.5 \%$. No severe conjunctival hyperemia was observed, either at baseline or at final visit in this patient subgroup (Figure 9).
The development of staining and LIPCOF is shown in Figures 10 and 11 for all patients with prior medical treatment, treatment-naïve patients and for different subgroups of patients.

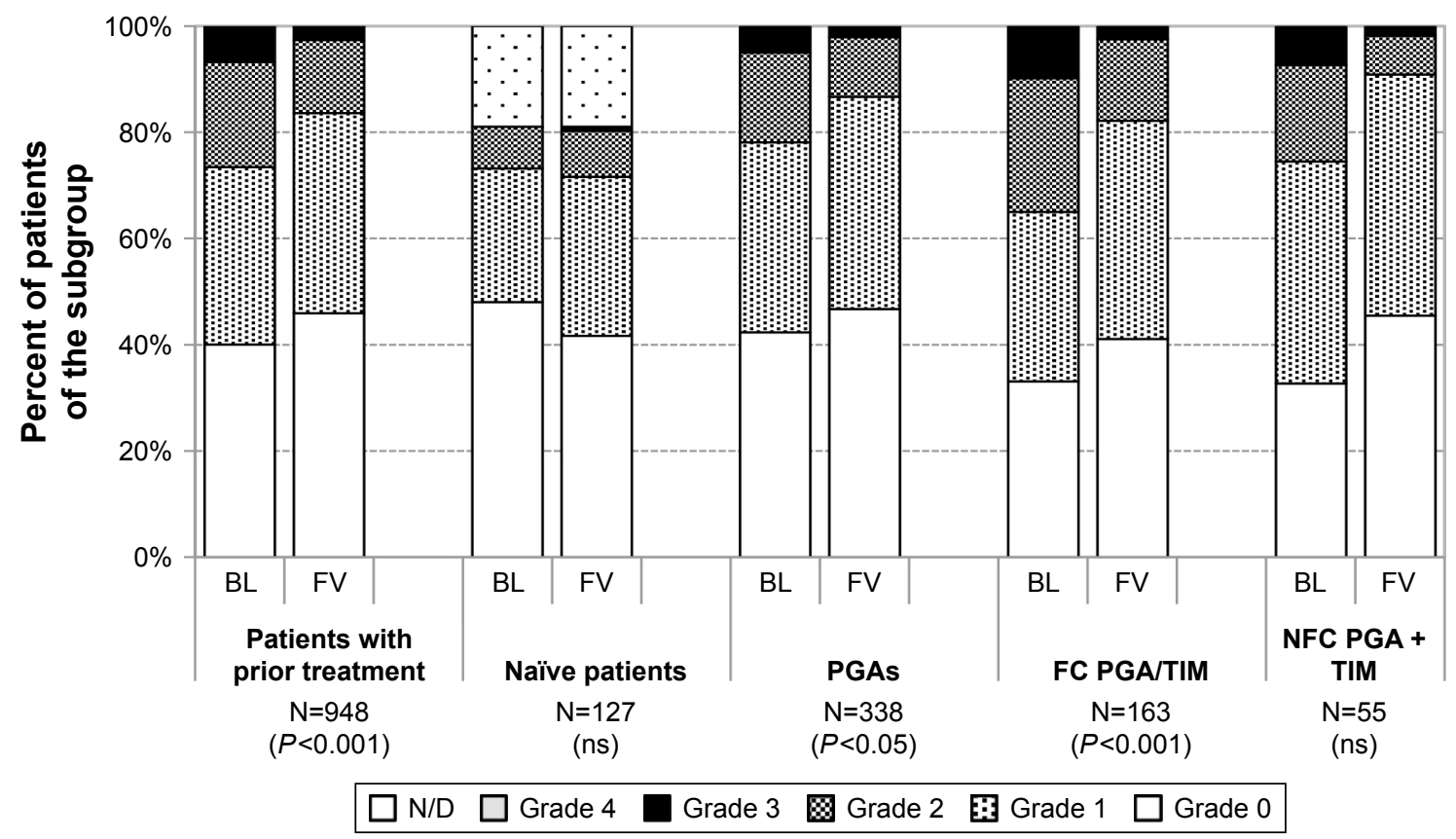

Figure I I Grading of lid-parallel conjunctival folds at baseline and after initiation of medical therapy with or change of medication in patients treated with preservative-free tafluprost/timolol fixed combination as the only medication at final visit: All patients with prior medical therapy ( $\mathrm{N}=948$ ), naïve patients ( $\mathrm{N}=127)$, patients with prior PGA monotherapy $(\mathrm{N}=338)$, patients with prior fixed combination PGA/timolol $(\mathrm{N}=163)$ and patients with prior nonfixed combination of a $\mathrm{PGA}$ and timolol $(\mathrm{N}=55)$. Abbreviations: BL, baseline; FC, fixed combination; FV, final visit; NFC, nonfixed combination; PGA, prostaglandin analog; TIM, timolol; N/D, no data; ns, not significant. 
Overall, improvements were also present for these two parameters. At baseline, conjunctival staining was present in $30.9 \%$ of all patients with prior medical treatment $(19.4 \%$ light, $10.2 \%$ medium and $1.3 \%$ intense). After change of medication to the preservative-free tafluprost/timolol fixed combination, the presence of conjunctival staining decreased to $21.7 \%$ (18.6\% light, $3.6 \%$ medium and $0.1 \%$ intense). Intense staining was more frequent in the subgroups of patients with prior PGA/timolol fixed- (1.2\%) and nonfixed combinations $(3.6 \%)$. Changes in conjunctival staining were found to be statistically significant $(P<0.01)$ in all patients with prior medical treatment, patients with prior PGAs and patients with prior PGA/timolol fixed combinations. No significant changes were found for the subgroups of treatment-naïve patients and patients with prior nonfixed combinations of PGAs and beta-blockers. LIPCOF were present at baseline in $59.9 \%$ of all patients with prior medical therapy. This percentage decreased significantly after change of medication to the preservative-free tafluprost/timolol fixed combination to $54.1 \%$. Further details for LIPCOF are shown in Figure 11.

\section{Ocular symptoms and local tolerability}

At baseline, dry eye symptoms, irritation, itching, foreign body sensation and eye pain were reported by $56.4,54.0$, $36.0,40.0$ and $18.0 \%$ of patients with prior medical therapy, respectively. Both the frequency and severity of these ocular symptoms improved significantly by the final examination compared to baseline $(P<0.001)$ (Figure 12). At final visit, dry eye symptoms, irritation, itching, foreign body sensation and eye pain were reported by 45.6, 33.3, 21.7, 22.4 and $8.9 \%$, respectively.

In the subgroup of treatment-naïve patients, dry eye symptoms, irritation, itching, foreign body sensation and eye pain were reported by $26.8,12.6,5.5,9.4$ and $1.6 \%$ of patients. Frequency and severity of these ocular symptoms increased slightly by the final examination compared to baseline. However, the difference was not statistically significant (Figure 13).

Local tolerability of the preservative-free tafluprost/ timolol fixed combination was rated as "very good" or "good" by $88.8 \%$ of all physicians for their patients and by $90.6 \%$ of the patients at the final visit.

\section{Safety and terminations of treatment}

Few adverse reactions were associated with the use of the preservative-free fixed combination leading to the termination of medical treatment during the observational study. One thousand and seventy-two patients $(92.7 \%)$ completed the study and continued with their medical treatment with the preservative-free fixed combination after final visit, either as the only medication or in combination with other glaucoma products. Twenty-five patients $(2.2 \%)$ terminated the treatment because of a lack of efficacy, 29 patients $(2.5 \%)$

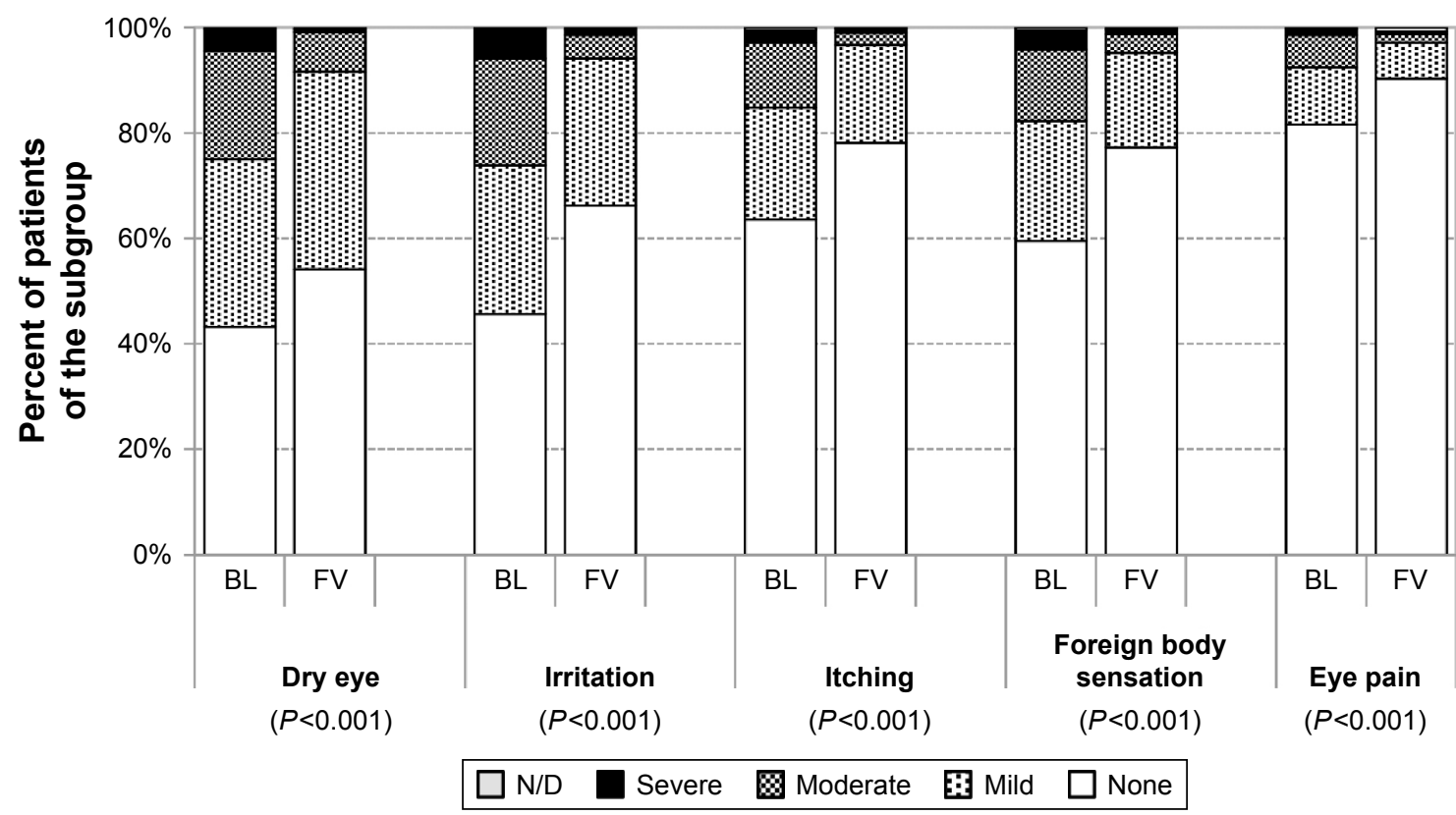

Figure 12 Severity of ocular symptoms in patients with prior medical treatment at baseline and after change of medication to the preservative-free tafluprost/timolol fixed combination ( $\mathrm{N}=948$ ).

Abbreviations: BL, baseline; FV, final visit; N/D, no data. 


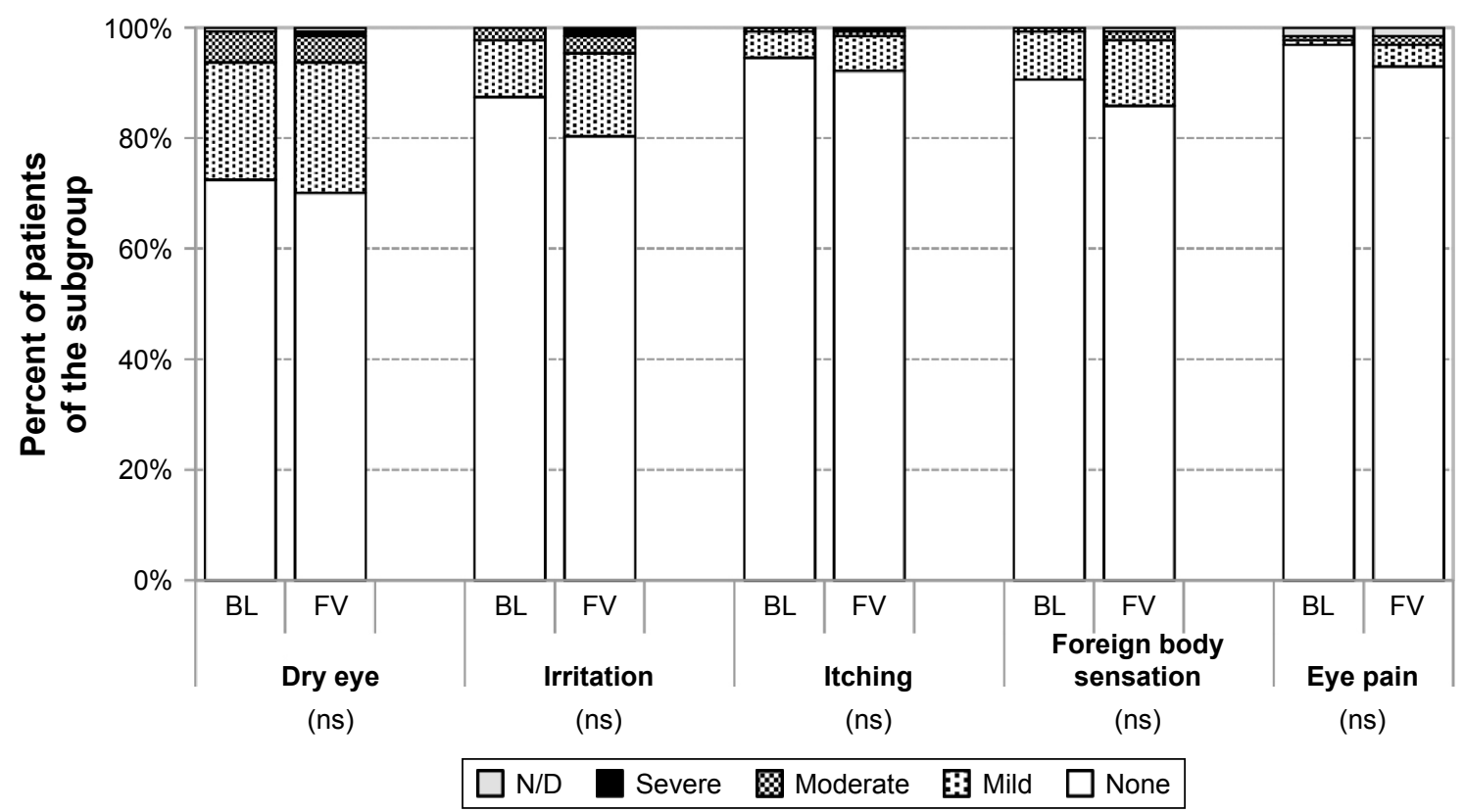

Figure 13 Severity of ocular symptoms in treatment naïe patients at baseline and at final visit after initiation of medical treatment with the preservative-free tafluprost/ timolol fixed combination ( $\mathrm{N}=127)$.

Abbreviations: BL, baseline; FV, final visit; N/D, no data; ns, not significant.

because of tolerability issues, most frequently conjunctival hyperemia (nine patients; $0.8 \%$ ) and seven patients $(0.6 \%)$ because of systemic intolerance. Only $0.3 \%$ of patients had handling issues with the unit doses, which led to the discontinuation of treatment. All details for the adverse events and terminations of treatment are shown in Table 3.

\section{Discussion}

The preservative-free tafluprost/timolol fixed combination lowered IOP effectively and statistically significantly in the overall study population of patients, in treatmentnaïve patients and in the different subgroups by prior medical treatment: in all patients who were treated with the preservative-free tafluprost/timolol fixed combination as the only medication at the final visit $(\mathrm{N}=1,075)$, mean IOP decreased significantly at final visit versus baseline by $4.9 \mathrm{mmHg}(-22.9 \%)$. At the final visit, individual IOPs were lower compared with baseline in $89.5 \%$ eyes, unchanged in $5.1 \%$ eyes and higher in $5.4 \%$ eyes. Interestingly, the IOP response seems to be dependent on the baseline IOP levels, which confirms earlier results: eyes with higher baseline IOP levels showed a higher absolute response and percentage IOP decrease as compared to eyes with lower baseline IOP levels. ${ }^{20}$ This result was found for patients with prior medical treatment and also for the subgroup of treatment-naïve patients. This finding seems to be particularly important for any outpatient glaucoma management, because in patients who require a switch to a combination therapy, usually no washout period is conducted. In the patient subgroup of treatment-naïve patients, mean IOP at baseline decreased significantly from $25.8 \pm 5.5$ to $16.9 \pm 2.9 \mathrm{mmHg}$ at final visit (-34.3\%). Furthermore, the results of the subanalysis by baseline IOP levels in this subgroup of treatment-naïve patients confirmed that the greatest response to the preservative-free tafluprost/timolol fixed combination is obtained in patients with higher baseline IOP levels. This finding is consistent with the results of a meta-analysis of double-masked, controlled phase III studies with fixed combination products of prostaglandin and timolol published by Holló et $\mathrm{al}^{20}$ and for other treatment options like selective laser trabeculoplasty. ${ }^{21,22}$ In the study of Hollo a similar reduction in IOP of $\sim 32 \%-36 \%$ from untreated baseline IOP levels between 24 and $29 \mathrm{mmHg}$ was reported. ${ }^{20}$ Furthermore, this meta-analysis revealed that IOP reductions of up to $40 \%$ and beyond could be achieved for untreated baseline pressures of $31 \mathrm{mmHg}$ or higher. The present study demonstrated IOP reductions between 36.7 and $61.9 \%$ in patients with prior medical treatment and baseline IOP levels of $>31 \mathrm{mmHg}$. In the subgroup of treatment-naïve patients, IOP was reduced by $51.6 \%$ in patients with untreated baseline IOP levels of $>31 \mathrm{mmHg}$. In a study with the preservative-free fixed combination of bimatoprost and timolol, the IOP reduction was statistically significantly greater in treatment-naïve patients than in previously treated patients after a wash-out period. Mean IOP was 
Table 3 Adverse events and terminations of treatment for the overall study population $(\mathrm{N}=\mathrm{I}, \mathrm{I} 157)$

\begin{tabular}{|c|c|c|}
\hline Reason for termination of treatment & Patients (N) & $\%$ \\
\hline Lack of efficacy (intraocular pressure) & 25 & 2.2 \\
\hline \multicolumn{3}{|l|}{ Adverse events } \\
\hline Systemic adverse events & 6 & 0.5 \\
\hline Asthmatic disease & I & 0.1 \\
\hline Beta-blocker contraindication & I & 0.1 \\
\hline Hair loss & I & 0.1 \\
\hline Hypertonia & I & 0.1 \\
\hline Vertigo & I & 0.1 \\
\hline Vertigo, palpitation & I & 0.1 \\
\hline Systemic and local adverse events & I & 0.1 \\
\hline Coughing, breathing issues, irritation & 1 & 0.1 \\
\hline Local adverse events & 29 & 2.5 \\
\hline Hyperemia & 3 & 0.3 \\
\hline Hyperemia, chemosis & I & 0.1 \\
\hline Hyperemia, foreign body sensation & I & 0.1 \\
\hline Hyperemia, eye pain & I & 0.1 \\
\hline Hyperemia, dry eye sensation & I & 0.1 \\
\hline Hyperemia, allergy & I & 0.1 \\
\hline Hyperemia, irritation & I & 0.1 \\
\hline Blepharitis & I & 0.1 \\
\hline Burning & 6 & 0.5 \\
\hline Burning, itching & 2 & 0.2 \\
\hline Burning, stinging & I & 0.1 \\
\hline Blurred vision, irritation & I & 0.1 \\
\hline Dry eye sensation & I & 0.1 \\
\hline Dry eye sensation, itching & I & 0.1 \\
\hline Dry eye sensation, tired eyes & I & 0.1 \\
\hline Eye pain, irritation & I & 0.1 \\
\hline Foreign body sensation & I & 0.1 \\
\hline Irritation & 3 & 0.3 \\
\hline Tearing, blurred vision & 1 & 0.1 \\
\hline Handling issue unit doses & 3 & 0.3 \\
\hline Compliance & 1 & 0.1 \\
\hline Patient preference & 4 & 0.3 \\
\hline Cost & I & 0.1 \\
\hline Unspecified reasons for termination & 15 & 1.3 \\
\hline Total terminations & 85 & 7.3 \\
\hline
\end{tabular}

Note: These also include patients who were treated concomitantly with the preservative-free tafluprost/timolol fixed combination at final visit.

reduced at various time points during the day between -8.7 and $-9.8 \mathrm{mmHg}$ after initiating medical treatment with the bimatoprost/timolol fixed combination. ${ }^{23}$ These findings are comparable to the results of the present study with a mean reduction of IOP of $8.9 \mathrm{mmHg}$ especially when considering the similar untreated baseline IOP levels. In another study comparing efficacy and safety of the preservative-free fixed combination of bimatoprost and timolol with the preserved formulation, Goldberg and co-workers found a similar IOP-lowering efficacy of both formulations of -9.16 to $-7.98 \mathrm{mmHg}$ for the bimatoprost/timolol preservative-free group, and from -9.03 to -7.72 for the preserved formulation. Between 86.3 and $90.6 \%$ of patients treated with the preservative-free bimatoprost/timolol fixed combination achieved at least a 20\% IOP reduction at week $12 .{ }^{24}$ These results are comparable to the findings of the present study in the subgroup of treatment-naïve patients.

The results of this open-label, multicenter observational study confirm earlier results that the preservative-free fixed combination tafluprost/timolol provides an effective IOP control in patients who are inadequately controlled on monotherapy, in patients with high baseline IOP levels and in patients who are sensitive to preservatives..$^{7-10,20}$ Usually fixed combinations are used in patients inadequately managed on monotherapy or in patients with multiple treatment regimens to reduce the number of applications and thus to reduce the complexity of medical treatment. ${ }^{1,25,26}$ Although fixed combinations are normally not used as a first-line treatment option, the EGS mentions that the use of fixed combinations may be considered in patients with high untreated baseline IOP levels, which are unlikely to achieve a sufficient target IOP level with a monotherapy treatment regimen. ${ }^{1}$ In the present study a large proportion of patients were switched from monotherapy treatment regimens with PGAs, beta-blockers, alpha-2-agonists and topical carbonic anhydrase inhibitors to the preservative-free tafluprost/ timolol fixed combination. In these patient groups mean IOP levels between 15.7 and $16.7 \mathrm{mmHg}$ were achieved after changing medication. The preservative-free tafluprost/ timolol fixed combination was found to provide significant additional IOP reduction in all of these subgroups of patients with prior monotherapy.

The preservative-free fixed combination was also effective in patients who were switched from nonfixed and fixed PGA/beta-blocker combinations: in patients who were switched from nonfixed PGA/beta-blocker combinations, mean IOP decreased from $18.7 \pm 3.3 \mathrm{mmHg}$ at baseline to $16.0 \pm 3.2 \mathrm{mmHg}(-14.4 \%)$. Mean IOP was also significantly lowered between 3.2 and $2.1 \mathrm{mmHg}$ in patients with different preserved fixed combinations of PGAs and timolol with medicated baseline IOP levels between 18.4 and $20.2 \mathrm{mmHg}$. On average in this patient subgroup mean IOP was reduced from $19.1 \mathrm{mmHg}$ at baseline to $16.7 \mathrm{mmHg}(-12.7 \%)$ at final visit after the change of medication to the preservative-free tafluprost/timolol fixed combination. In a study evaluating the effects of a change of medication from a fixed combination of bimatoprost and timolol to a fixed combination of travoprost and timolol, mean IOP was reduced from 20.0 to $16.8 \mathrm{mmHg}$ $(-18.5 \%)$ after 12 weeks. Moreover, in this study, also no washout period was established between run-in period and final visit. ${ }^{27}$ This IOP reduction is comparable to our results, 
even when considering the approximately $1 \mathrm{mmHg}$ higher baseline IOP level.

In addition to efficacy, local tolerability and clinical signs are important factors for patients with chronic diseases such as glaucoma. Human and animal studies have shown that chronic topical glaucoma therapy preserved with BAK can be associated with alterations of the tear film, and that it provokes tear film instability, induces changes and damage of the ocular surface, and epithelial apoptosis, increases inflammatory cytokines and induces a loss of conjunctival goblet cells, and the outcome of glaucoma surgery is significantly worsened after prior treatment with BAK containing eye drops. ${ }^{13,15,16,29-33}$ Significant levels of BAK were found in iris, lens capsule or trabecular meshwork (TM) tissue of rabbits after topical exposure, thus confirming the penetration of BAK in deep ocular structures, with potential deleterious effects induced by this cytotoxic compound. ${ }^{31,32}$ Furthermore, it could be demonstrated in in vitro assays of cultured human TM tissues that BAK demonstrated a dosedependent reduction in TM cell viability and that the BAK treatment appeared to cause elevated levels of MMP-9, a matrix metalloproteinase implicated in the pathogenesis of glaucoma. ${ }^{33}$ These findings may be of specific importance in patients with more advanced stages of glaucoma requiring a combination therapy. Finally, there is evidence that the prevalence of ocular surface disorders is high in glaucoma patients: in a study by Leung et al, $59 \%$ of patients with open-angle glaucoma or ocular hypertension reported dry eye symptoms in at least one eye. ${ }^{34}$ In another study by Erb et al, dry eye syndrome was diagnosed in $52.6 \%$ of glaucoma patients. ${ }^{35}$ In both studies, the occurrence of dry eye syndrome increased with the number of preservative-containing antiglaucoma drugs used. After changing medication either from prior PGA monotherapy, PGA/timolol fixed or nonfixed combinations to the preservative-free tafluprost/timolol fixed combination, subjective symptoms and clinical signs such as hyperemia, LIPCOF and staining improved significantly in most patients. Results from this study suggest that patients with irritation of the ocular surface, subjective symptoms and clinical changes of the ocular surface may benefit from a change of medication to the preservative-free tafluprost/ timolol fixed combination. Regarding local tolerability of glaucoma medications, clinical studies show that a relatively high proportion of glaucoma patients develop symptoms like burning and stinging, foreign body sensation, dry eye and irritation of the ocular surface. These ocular symptoms are reported significantly less often in patients receiving preservative-free preparations. ${ }^{17,18}$ In this study, subjective symptoms improved at final visit compared to baseline, especially in the subsets of patients treated with prior PGA monotherapy, PGA/timolol fixed and nonfixed combinations. The preservative-free tafluprost/timolol fixed combination was generally well tolerated and showed a favorable safety profile: 1,072 patients $(92.7 \%)$ continued with their medication after final visit, which confirmed the findings from controlled clinical trials. ${ }^{36}$

This observational study is limited by its open-label design. Due to its observational nature, the study did not reveal any causal relationships. However, the study design of the present study may better reflect the treatment algorithms in day-to-day practice. The observed IOP reduction after switching might be ascribed not only to the improvement of subjective symptoms and clinical signs and thus a better compliance, but also to the patient population at baseline itself. However, regression to the mean cannot be ruled out because a control group was not used. Overall the preservative-free tafluprost/timolol fixed combination showed a favorable IOP-lowering effect over 12 weeks in all patient subgroups including treatment-naïve patients, thus representing an effective IOP-lowering alternative for patients who require lower target IOP levels and who would benefit from preservative-free eyedrops.

\section{Conclusion}

The preservative-free fixed combination tafluprost/timolol was efficacious and well tolerated with a good safety profile in the diverse patient population of this observational study. The fixed combination provided further IOP reduction in patients with poor IOP control and/or poor tolerance of their medication prior to change of medication. Thus, the preservative-free fixed combination tafluprost/timolol provides a new well-tolerated and convenient therapeutic option, especially for patients whose IOP is uncontrolled with a monotherapy and for patients who are unable to tolerate preserved combination treatment regimens.

\section{Acknowledgments}

This study was financially supported by Santen Oy, Tampere, Finland.

\section{Author contributions}

Medical writing, data management and statistical analysis of the present study were done by eyecons (F Kimmich). All authors contributed toward data analysis, drafting and critically revising the paper and agree to be accountable for all aspects of the work. 


\section{Disclosure}

LE Pillunat, N Pfeiffer and C Erb are consultants/advisors and speakers for Santen Oy. A Ropo is an employee of Santen Oy. F Kimmich is a consultant for Santen Oy from which he received financial support. The authors report no other conflicts of interest in this work.

\section{References}

1. European Glaucoma Society (EGS). Terminology and Guidelines for Glaucoma. 4th edition. Savona, Italy: Publicomm; 2014:140.

2. Lundberg LU, Thygeson J, Damgard-Jensen L, et al. Glaucoma patients treated by practicing ophthalmologists in Denmark. Estimated number of patients and the extend of visual field defects. Ugeskr Laeger. 2000;162:3028-3033.

3. Schwabe U, Paffrath D. Prescription report for pharmaceuticals 2011. Actual data, cost, trends and commentaries [Arzneiverordnungs-Report 2011. Aktuelle Daten, Kosten, Trends und Kommentare] in German. Heidelberg, Germany: Springer; 2012:770-778.

4. Kass MA, Heuer DK, Higginbotham EJ, et al. The Ocular Hypertension Treatment Study: a randomized trial determines that topical ocular hypotensive medication delays or prevents the onset of primary open angle glaucoma. Arch Ophthalmol. 2002;120(6):701-713.

5. Higginbotham EJ. Considerations in glaucoma therapy: fixed combinations versus their component medications. Clin Ophthalmol. 2010; 4:1-9.

6. Higginbotham EJ, Hansen J, Davis EJ, Walt JG, Guckian A. Glaucoma medication persistence with a fixed combination versus multiple bottles. Curr Med Res Opin. 2009;25(10):2543-2547.

7. Konstas AG, Holló G. Preservative-free tafluprost/timolol fixed combination: a new opportunity in the treatment of glaucoma. Expert Opin Pharmacother. 2016;17(9):1271-1283.

8. Hoy SM. Tafluprost/Timolol: a review in open-angle glaucoma or ocular hypertension. Drugs. 2015;75(15):1807-1813.

9. Holló G, Hommer A, Antón López A, Ropo A. Efficacy, safety, and tolerability of preservative-free fixed combination of tafluprost $0.0015 \% /$ timolol $0.5 \%$ versus concomitant use of the ingredients J Ocul Pharmacol Ther. 2014;30(6):468-475.

10. Pfeiffer N, Traverso CE, Lorenz K, et al. A 6-month study comparing efficacy, safety, and tolerability of the preservative-free fixed combination of tafluprost $0.0015 \%$ and timolol $0.5 \%$ versus each of its individual preservative-free components. Adv Ther. 2014;31(12):1228-1246.

11. Baudouin C, Labbé A, Liang H, et al. Preservatives in eyedrops: the good, the bad and the ugly. Prog Retin Eye Res. 2010;29(4):312-334.

12. Baudouin C. Detrimental effect of preservatives in eyedrops: implications for the treatment of glaucoma. Acta Ophthalmol. 2008;86(7):716-726.

13. Baudouin C, Liang H, Hamard P, et al. The ocular surface of glaucoma patients treated over the long term expresses inflammatory markers related to both T-helper 1 and T-helper 2 pathways. Ophthalmology. 2008;115(1): $109-115$.

14. Noecker R. Effects of common ophthalmic preservatives on ocular health. Adv Ther. 2001;18(5):205-215.

15. Rasmussen CA, Kaufman PL, Kiland JA. Benzalkonium chloride and glaucoma. J Ocul Pharmacol Ther. 2014;30(2-3):163-169.

16. Kahook MY, Noecker R. Quantitative analysis of conjunctival goblet cells after chronic application of topical drops. Adv Ther. 2008; 25(8):743-751.

17. Jaenen N, Baudouin C, Pouliquen P, Manni G, Figueiredo A, Zeyen T. Ocular symptoms and signs with preserved and preservative-free glaucoma medications. Eur J Ophthalmol. 2007;17(3):341-349.

18. Pisella PJ, Pouliquen P, Baudouin C. Prevalence of ocular symptoms and signs with preserved and preservative free glaucoma medication. Br J Ophthalmol. 2002;86(4):418-423.
19. Nordmann JP, Auzanneau N, Ricard S, Berdeaux G. Vision related quality of life and topical glaucoma treatment side effects. Health Qual Life Outcomes. 2003;1:75.

20. Holló G, Vuorinen J, Tuominen J, Huttunen T, Ropo A, Pfeiffer N. Fixed-dose combination of tafluprost and timolol in the treatment of open-angle glaucoma and ocular hypertension: comparison with other fixed-combination products. Adv Ther. 2014;31(9):932-944.

21. Chun M, Gracitelli CP, Lopes FS, Biteli LG, Ushida M, Prata TS. Selective laser trabeculoplasty for early glaucoma: analysis of success predictors and adjusted laser outcomes based on the untreated fellow eye. BMC Ophthalmol. 2016;16(1):206.

22. Pillunat KR, Spoerl E, Elfes G, Pillunat LE. Preoperative intraocular pressure as a predictor of selective laser trabeculoplasty efficacy. Acta Ophthalmol. 2016;94(7):692-696.

23. Cordeiro MF, Goldberg I, Schiffman R, Bernstein P, Bejanian M. Efficacy of a preservative-free formulation of fixed-combination bimatoprost and timolol (Ganfort PF) in treatment-naïve patients versus previously treated patients. Clin Ophthalmol. 2015;9:1605-1611.

24. Goldberg I, Pina RG, Lanzagorta-Aresti A, Schiffman RM, Liu C, Bejanian M. Bimatoprost $0.03 \% /$ timolol $0.5 \%$ preservative-free ophthalmic solution versus bimatoprost $0.03 \% /$ timolol $0.5 \%$ ophthalmic solution (Ganfort) for glaucoma or ocular hypertension: a 12-week randomised controlled trial. Br J Ophthalmol. 2014;98(7):926-931.

25. Robin AL, Covert D. Does adjunctive glaucoma therapy affect adherence to the initial primary therapy? Ophthalmology. 2005;112(5):863-868.

26. Robin AL, Novack GD, Covert DW, Crockett RS, Marcic TS. Adherence in glaucoma: objective measurements of once-daily and adjunctive medication use. Am J Ophthalmol. 2007;144(4):533-540.

27. Schnober D, Hubatsch DA, Scherzer M. Efficacy and safety of fixedcombination travoprost $0.004 \% /$ timolol $0.5 \%$ in patients transitioning from bimatoprost $0.03 \% /$ timolol $0.5 \%$ combination therapy. Clin Ophthalmol. 2015;9:825-832.

28. Noecker RJ, Herrygers LA, Anwaruddin R. Corneal and conjunctival changes caused by commonly used glaucoma medications. Cornea. 2004;23(5):490-496.

29. Martone G, Frezzotti P, Tosi GM, et al. An in vivo confocal microscopy analysis of effects of topical antiglaucoma therapy with preservative on corneal innervation and morphology. Am J Ophthalmol. 2009;147(4):725-735.

30. Vaede D, Baudouin C, Warnet JM, Brignole-Baudouin F. [Preservatives in eye drops: toward awareness of their toxicity]. J Fr Ophthalmol. 2010; 33(7):505-524. French.

31. Baudouin C, Denoyer A, Desbenoit N, Hamm G, Grise A. In vitro and in vivo experimental studies on trabecular meshwork degeneration induced by benzalkonium chloride (an American Ophthalmological Society thesis). Trans Am Ophthalmol Soc. 2012;110:40-63.

32. Desbenoit N, Schmitz-Afonso I, Baudouin C, et al. Localisation and quantification of benzalkonium chloride in eye tissue by TOF-SIMS imaging and liquid chromatography mass spectrometry. Anal Bioanal Chem. 2013;405(12):4039-4049.

33. Ammar DA, Kahook MY. Effects of benzalkonium chloride-or polyquad-preserved fixed combination glaucoma medications on human trabecular meshwork cells. Mol Vis. 2011;17:1806-1813.

34. Leung EW, Medeiros FA, Weinreb RN. Prevalence of ocular surface disease in glaucoma patients. J Glaucoma. 2008;17(5):350-355.

35. Erb C, Gast U, Schremmer D. German register for glaucoma patients with dry eye. I. Basic outcome with respect to dry eye. Graefes Arch Clin Exp Ophthalmol. 2008;246(11):1593-1601.

36. Holló G, Katsanos A. Safety and tolerability of the tafluprost/timolol fixed combination for the treatment of glaucoma. Expert Opin Drug Saf. 2015;14(4):609-617. 


\section{Publish your work in this journal}

Clinical Ophthalmology is an international, peer-reviewed journal covering all subspecialties within ophthalmology. Key topics include: Optometry; Visual science; Pharmacology and drug therapy in eye diseases; Basic Sciences; Primary and Secondary eye care; Patient Safety and Quality of Care Improvements. This journal is indexed on

Submit your manuscript here: http://www.dovepress.com/clinical-ophthalmology-journal
PubMed Central and CAS, and is the official journal of The Society of Clinical Ophthalmology (SCO). The manuscript management system is completely online and includes a very quick and fair peer-review system, which is all easy to use. Visit http://www.dovepress.com/ testimonials.php to read real quotes from published authors. 